\title{
A Career In Public Health Medicine
}

\author{
A H McG Macmillan
}

\section{Introduction}

The primary role of the Army Medical Services (AMS) is the maintenance of health and the prevention of disease. This statement does not set out to belittle the other vital roles (collection, treatment and evacuation of the wounded or the supply of medical materiel) but emphasises that wherever soldiers serve, and whether or not there is a likely physical or enemy threat to them, there is an underlying potential set of challenges to their health, and thus their availability for employment. Many specialist branches within the AMS make a contribution towards this primary aim but only one is totally focused on it: public health medicine (PHM).

The primary role has a key word within it: health. The World Health Organisation (WHO) (1) defined this as "a state of complete physical, mental and social well-being and not merely the absence of disease or infirmity". It is not an absolute concept and one must be clear that there is a continuum of health status, between well-being and ill-health, held by individuals. The definition has had many adjustments and additions since it was first articulated in 1948 and in a military context, the WHO conception must be broadened to embrace fitness in addition to well-being. Indeed, a pragmatic AMS has now defined (2) health as the ability to carry out duties unimpeded by physical, psychological and social factors. There are five interacting factors which determine health:

- Biological - genetic, aging

- Environment including communicable disease

- Life style - exercise, diet, behaviour

- Social and economic

- Use of, and access to, health services

The last factor, health services, has a relatively small part to play compared with the others, albeit one which is heavily demanding of resources. Arguably, the interrelationship of the first four factors determines the role the fifth factor ultimately plays.

Brig A $\mathrm{H} \mathrm{McG}$

Macmillan

QHP MB ChB MPH

FFPHM late RAMC

Defence Consultant

Adviser in Public

Health Medicine

Email: ironfist@cqm.co.uk

These determinants affect individuals individuals add up to populations or the public at large. The concept thus moves on to considering the wider public health $(\mathrm{PH})$. $\mathrm{PH}$ can be defined (3) as "the science and art of preventing disease, prolonging life and promoting health through the organised efforts of society". PHM then is that branch of

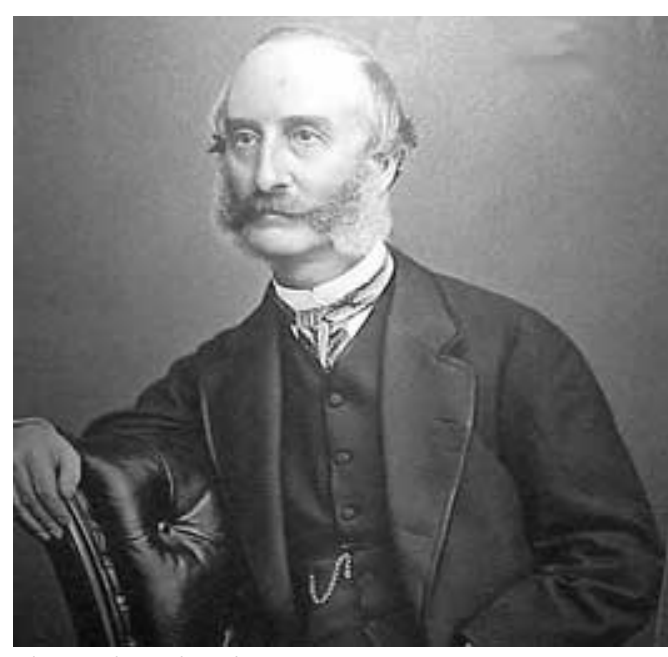

Fig 1. Edmund Parkes

medicine that is heavily engaged in $\mathrm{PH}$.

\section{History}

The PH movement stems from the mid 19th Century when society started to get to grips with the scourge of epidemic disease. It was based on sanitary hygiene and epidemic disease control. In parallel, the military started to address the issue. Disease had traditionally caused armies far more mortality and morbidity than the enemy ever had. The Crimean War was in many ways the nadir of such military experience and in the fall-out of that campaign a Professor of Hygiene, Edmund Parkes (Figure 1), was appointed and became the father of Army Hygiene, later to become Army Health.

Army Health encompassed $\mathrm{PH}$, environmental health and industrial health. This overarching approach remained until the 1970s when civilian colleagues moved into two distinct groupings with their own academic qualifications: occupational medicine and community medicine. The two disciplines had some common ground and skills but were significantly diversifying in the light of medical and scientific advance. In the 1980 s, community medicine reverted to the title of PHM. This happened because society had almost forgotten about communicable disease and had become susceptible again to its ravages.

\section{Public Health Medicine Today}

The core skill and tool of $\mathrm{PH}$ is epidemiology. This is defined (4) as "the study of the distribution and determinants of healthrelated states or events in specified populations, 
and the application of this study to control of health problems". In this context, study includes surveillance, observation, hypothesis testing, analytic research and experiments. Distribution is about the analysis by time, place and classes of persons affected. The determinants have already been listed in the introduction. Health-related states include diseases, causes of death, behaviours such as tobacco use, reactions to preventive regimens and the provision and use of health services. Control makes explicit the aim of epidemiology which is to promote, protect and restore the $\mathrm{PH}$.

This is a wide ranging brief and has two principal sequelae, thinking about populations, as opposed to individual patients, and taking a longer term view on events beyond a consultation, clinical intervention or full consultant episode. It also means mastering skills and competences in a number of related subjects, notably health economics, statistics, health psychology, health sociology, health education and promotion and management theory. Vitally, the gathering and management of health and social information is critical to an effective $\mathrm{PH}$ service. It is a rigorous, science (evidence)based discipline which will assess health needs then go on to assess the effectiveness of health outcomes through evaluation. Health protection from both communicable disease and environmental hazards remains a cornerstone of PHM.

The PH function is, therefore, best undertaken where it can effectively prosecute its functions and gain access to both information and the influences on the determinants of health. In civilian life this ranges from local health authorities and health boards to districts, regions and ultimately the Department of Health $(\mathrm{DoH})$ or devolved government.

Even with the periodic reorganisations that bedevil the NHS, such as the new departure from district health authorities to primary care groups and strategic health authorities, the $\mathrm{PH}$ function still has to inform the working of these organisations. In the Armed Forces, the $\mathrm{PH}$ function therefore happens at formation headquarters level (UK and Germany) and in the Ministry of Defence (MOD). It has a strong presence in both the Surgeon General's Department (SGD) and the Army Medical Directorate (AMD). It is equally applicable in a peace-time setting as in the operational deploy-ment.

The PHM cadre has two subtly variant strands. The first is a group of individuals that combine main-stream command and staff with their specialty. Indeed, $\mathrm{PH}$ training, skills and competences are ideal ones for a medical staff officer. The second group spend most of their time in $\mathrm{PH}$ employment, still on the medical staff but purely in their specialist area.

Collaborative working is another vital attribute. As society at large begets its Armed Forces, so relating the military sub-set of the population to the whole is necessary. Health standards and services for dependants stem from civilian requirements. Health services for soldiers are being provided increasingly by the NHS. Thus PH is central to the functioning of the DoH-MOD interface and an understanding of the NHS is vital for military PHM. The NHS also provides reservist PHM officers who are available to increase the deployable workforce during large military deployments.

\section{Selection and training}

There is scope for the employment of about 12 PHM consultants in the Armed Forces, the majority coming from the AMS. This includes those in more main-stream command and staff and there are up to six training posts recognised by the Faculty of PHM.

Training is mainly in-house for the range and scope of the core PHcompetences can be comfortably attained working in military $\mathrm{PH}$. However, a period of 6 months must be spent seconded to the NHS so that a wider view of the population can be developed and an understanding of NHS organisation and current issues can be taken forward towards successfully passing the Faculty's examinations.

In order to start training, applicants must first satisfy the Post Graduate Dean and the RAMC Post-graduate Council that they are suitable. They must have completed general professional training of at least 2 years post registration. However, the norm will be somebody who has completed General Practice Vocational Training (GPVT) before they turn to the speciality. Occasionally, medical officers from the hospital-based specialties, either fully trained consultants or specialist registrars ( $\mathrm{SpR})$, apply for training.

A successful initial interview with the Consultant Adviser in PHM is a necessary preamble to the application since he not only sits on the Council and advises the Dean, but is the best vehicle for access to the various application forms and their proper completion.

Under the Dean's aegis a suitable NHS $\mathrm{SpR}$ appointment board is identified and the potential military $\mathrm{SpR}$ undertakes this in parallel with civilian counterparts. Whilst they are not in competition for the same jobs, reasonable quality comparisons can be made in order to inform selection. The Dean and Consultant Adviser both sit on the relevant local NHS board. Following a successful selection outcome, the Dean will issue a DMS National Training Number (NTN) and the $\mathrm{SpR}$ is then lined up with an approved training post. The $\mathrm{SpR}$ then registers with the Faculty as a trainee so that the RITA process can be monitored through training. SpRs will not be issued with their 
NTN until they have applied, and been accepted for, an Intermediate Regular Commission.

Following a short induction course held at the AMD Health Unit (and perhaps a short attachment to the NHS), SpRs are sent to a suitable University to study for a Master in $\mathrm{PH}(\mathrm{MPH})$ degree. With additional study, this is significant preparation for the Faculty's Part 1 Membership examination and this is taken towards the end of that academic year. The MPH course does not, however, count as in-service training for the $\mathrm{SpR}$. With the development of the Centre for Defence Medicine in Birmingham, future DMS SpRs will undertake their MPH training there.

There are training posts at SGD, AMD, UKSC(G), PJHQ and formation HQs. Their activation is dependent on the availability of a current PHM consultant trainer in situ. Specialist registrars will not be sent to posts where there is no trainer (military or civilian) present. Each post is recognised by the Faculty for 2 years worth of training and thus each SpR will hold two posts in his or her training in order to meet the requirement for 4 years in approved training posts. Some posts suit only early or late training so placement is designed around the needs of the individual $\mathrm{SpR}$.

SpRs are expected to submit work for the Faculty's Part 2 Membership examination during their in-service training. This is usually completed during the third year as the examination is required to exit the training programme and is needed for the Certificate of Completion of Specialist Training (CCST). The final year of training should then be available for consolidation of training and preparing to become a consultant. Exit from the programme has to be a minimum of 2 years post-Part 1 examination so failure in that examination and its carriage over into in-service training may delay final exit from the training programme and the achievement of a CCST.

\section{Assessment}

In-service training, in common with all other consultant-training specialities, is monitored and assessed by the RITA process. This is conducted annually (and occasionally more frequently as required for individual needs) in order to review progress and the attainment of $\mathrm{PH}$ competences. The panel consists of the Dean, the Consultant Adviser and an external experienced trainer from the NHS. Specialist SpRs now compile a detailed portfolio, as dictated by the Faculty, which charts progress, work and the competencies gained and this is critical in informing the RITA process.

Successful completion of the membership examination (MFPHM) and being signed off by the RITA process allows the Faculty to apply for a CCST for the SpR. Armed with this, application for an Armed Services Consultant Appointment Board (ASCAB) can be made through the Dean. Each ASCAB is specialty dependant and composed of civilian appointees although both the Dean and the Consultant Adviser are in attendance.

\section{Continuing Medical Education}

Training does not, however, finish with appointment as a consultant and posting to a suitable post. PHM involves an acceptance of life-long learning and the specialty is committed to Continuing Professional Development (CPD). To remain in good standing as a consultant, a record of CPD is required of each consultant and is submitted to the Faculty annually. Indeed, without this evidence, it is not possible to become a trainer or play any part as a Faculty officer, committee member or visitor. CPD will also be a vital part of annual appraisal and revalidation as a practitioner in PHM quite soon.

\section{Becoming a Trainer}

After 2 years experience as a consultant, one can become a trainer and the AMS is keen that all its PH Consultants are engaged and qualified in training.

\section{Moving on from here}

Consultants in PHM are paid on consultant rates. They can become, in time, eligible for distinction awards just as their hospital and civilian colleagues can.

Military staff training is independent of professional training and courses such as the Intermediate Command and Staff Course will have to be fitted in before or after formal $\mathrm{PH}$ training.

Those wishing to follow a more communicable disease control orientated pathway can have a suitably modified training programme constructed which will lead to an ASCAB which could select a consultant in communicable disease control.

The world wide scope of military deployments these days has led to the need to encourage AMS PHM consultants to take the Diploma in Hygiene and Tropical Medicine (DTM\&H). This is undertaken in addition to normal in-service training. It does not count, presently, towards the mandatory 4 years in training.

There is scope for 6 month SHO placements for GPVTs at AMD. To date there is no formal clearance for this from the Faculty but should there be any interested potential applicants then recognition arrangements can be quickly put in place.

\section{The Role of Other Specialities}

The Government's White Paper (5), Saving Lives, Our Healthier Nation, introduced the 
idea that future NHS Directors of PH would not necessarily have to be medical practitioners. This would be dependent on there being suitably trained and experienced multi-disciplinary $\mathrm{PH}(\mathrm{MDPH})$ specialists available. PH has always been multidisciplinary in nature and a very broad church. It will still require, in particular, health protection consultants but health economists, statistic-ians, health promoters, professions allied to medicine and many others, all play their part in the $\mathrm{PH}$ function and are well capable of developing a portfolio of competences which will allow them to meet the needs of a great number of posts.

The Faculty has already opened its Membership by examination to MDPH specialists and Deaneries are including $\mathrm{MDPH}$ trainees on their SpR programmes. They are also being assessed through the RITA process. Indeed, the AMS has its first MDPH trainee, an experienced health services manager and pharmacist, on its training programme. This should not be seen as a threat to medical officers as there still requires to be a mix of doctors and others. Health protection is vital to the AMS and medical officers are well placed to meet the examination challenges which will remain at the high standard of today.

Further details on PHM and MDPH training can be found on the Faculty's website: www.fphm.org.uk/

\section{Conclusion}

PHM is a varied and challenging career in the AMS. It contributes massively to the effectiveness of the Army. It provides an unequalled opportunity to work with those that determine the style and direction of the Army and how it employs its soldiers. It is intellectually stimulating and professionally satisfying. However, it is essential to develop patience and take a longer view on life than sometimes fits into the military culture.

\section{References}

1. WHO Constitution 1948.

2. AMS Core Doctrine pamphlet 1 - Principles.

3. HMSO. Public Health in England. Cmd 289, January 1988.

4. Last J M. A Dictionary of Epidemiology, 4th Edition, p 62. LEA 2001.

5. HMSO. Saving Lives, Our Healthier Nation. Cmd 4386, July 1999. 